\title{
Youths and the Guatemalan Return Process
}

\author{
Linda Geggie
}

Many of the Guatemalan refugee youths who are now returning to Guatemala after spending their formative years in Mexico are finding the reintegration process very difficult. Others, still in Mexico, are choosing not to return. Some of those who have returned to Guatemala have decided that life in Mexico is preferable and have already moved back to Mexico or are planning to do so. In this report I explore why the return to Guatemala is so difficult for some youths and less so for others. I report the case of one youth in particular who speaks for many others who have decided to return, despite the difficulties of reintegration.

\section{Displacement, Life Style and Identity}

The majority of the Guatemalan refugees in Mexico have been living there for over ten years. This is a long period of time, particularly for youths who scarcely remember Guatemala. Living abroad has been a profound experience for all, but particularly for the younger generation, because the communities they grew up in were very different from the ones their parents knew.

At first many Guatemalan refugees settled in temporary camps just across the Mexican border in the state of Chiapas, but due to the Guatemalan government's accusations that these were bases for the guerillas, and the fact that on several occasions the Guatemalan army crossed into Mexican territory to attack these populations, the Mexican government chose to move the camps away from the border. Approximately twenty thousand

Linda Geggie belongs to the Environmental Youth Alliance in Victoria, British Columbia. From June to December 1993, she worked in Guatemala as a Human Rights Observer with Project Accompaniment Canada. For most of this time she lived in Victoria 20 de enero, the community established by the first large group of refugees to return from Mexico. refugees were moved north to the states of Campeche and Quintana Roo in the Yucatán region, while the majority remained in Chiapas.

The settlement process in Mexico had two consequences for community culture and lifestyle in the camps. Firstly, it led to the formation of new communities in which the families living together came from different linguistic and cultural groups in Guatemala. This served to fracture and undermine traditional language and culture. There are 127 different refugee camps in Mexico containing families from different origin communities. Second, dispersal led to communities being established in regions throughout Mexico. In some cases, the new communities were similar to those in Guatemala. In other cases, they were quite different. Despite this diversity, adult refugees have retained strong ties to the land and their home-Guatemala. This is not necessarily the case for their children in the refugee camps. Those who grew up in Mexico have little or no memory of life in Guatemala, and are less attached to their traditional culture. In some cases they may be more attached to Mexican society.

Refugees who were settled in Chiapas found land, environment and cultural conditions similar to what they had known in Guatemala. However, the camps in the states of Quintana Roo and Campeche, both within the Yucatán region of Mexico, are very different from those both in Chiapas and in Guatemala. There are only eight camps in Quintana Roo and Campeche. Yet their populations are quite large and ethnically mixed, including Kanjobal, Mam, Jakalteko, Kakchiquel, Chuj, K'eche, Usspanteco and Qeq'chi indigenous groups.

Youths who grew up in camps in the Yucatán region of Mexico face the most extreme challenges in reintegration. The Yucatán area of Mexico, with its huge tourist and North American influence, has an entirely different cultural framework and reality. This has had an enormous impact on the refugee populations living there, especially for the youths with little recollection of life in Guatemala. Refugees in the Yucatán have been exposed to a better standard of living. Some have worked in the tourist areas of Cozumel, Merida and glitzy Cancun. Others have found work as construction workers, gardeners, domestics, child care workers, or in the hotels or restaurants of the tourist areas. They have been exposed to Western rock and rap music, magazines, television, videos, movies and clothing styles. It is a completely different world which has changed their way of thinking and undermined their traditional identity and lifestyle.

In the camps in the Yucatán, many refugee youths between thirteen and twenty years of age have become "Mexicanized," adopting the dress, language and attitudes of the land where they grew up. This new identity has wide ramifications for youths who are returning, and for the reintegration process in Guatemala in general. The life they are returning to is essentially foreign.

The impact of life in the Yucatán region is clearly evident in the story of Ernestina, a young Guatemalan woman of eighteen years of age who has spent nearly all of her life in a refugee camp in Campeche. She returned to Guatemala in January 1993 and now lives with her family in Victoria 20 de enero, the community established by the first large group of returnees from Mexico.

\section{Through Ernestina's Eyes}

Ernestina is a Mam Mayan Indian. She was born in Barillas, Huehuetenango, into a family of ten. In 1980, her family fled the rising violence of the civil war in Guatemala. She recalls the moment 
of flight: "We spent a lot of nights hiding in the forest, we did not sleep." The initial trauma of dislocation passed as the family slowly regained their security. They first lived for eight months in an area just across the Mexican border near the town of Puerto Rico. Later they were moved to a camp called Maya Tecun in Campeche state. They lived there for five years until they were relocated once again to a nearby camp, Santiago Domingo Castille, where they stayed until they returned to Guatemala. Ernestina spent thirteen of her eighteen years in Mexico. She says she did not remember very much about Guatemala, only the fact that they had to leave and hide in the mountains. In contrast, her life in Mexico remains ever present in her mind.

Ernestina looks and dresses differently from the older women in Victoria 20 de enero. As we sit drinking coffee, I look around her family's house. It is like the others in Victoria, with a dirt floor, no electricity, no running water, walls of assorted pieces of wood, boards and plastic, a fire to cook on, raised wooden beds with mosquito nets, and a latrine out back. It is basic living, but there are some things in the house that seem out of place in the middle of the Ixcan jungle.

We are listening to one of her many pop-techno-rap tapes on her ghetto blaster. There is a poster of the popular music group "Menudo" on the wall, sitting on the shelf is a basket of nail polishes of assorted colours, and in the corner, half buried by a sack of corn, sits a small television. Unlike her parents, coming back to Guatemala was not a happy move for Ernestina. She tells me that when she was in Mexico she lived in a house with a cement floor, electricity and running water. Cars and bicycles came right to the house. She lived with her family and worked as an education promoter. When her father told her they were returning back to Guatemala, her first reaction was to say 'No! She would stay in Mexico!'. The contrasts between her former life in Mexico and her current life in Guatemala are stark. Speaking of Mexico, Ernestina says,
Here there are no places to go... the roads are bad. [There,] we had our own trucks, and there were buses, [so] we went to nearby towns. My friends could find work if they wanted, to clean, or look after children, they could earn five hundred pesos (equivalent of about US\$170) per month, or they could work in construction of hotels, houses, or buildings. I was lucky, I was working as an education promoter, and I liked it a lot. Here there is no work, I went to look in Cantabal (a nearby commercial center). I could only find workin a restaurant for 250 Quetzales (about US\$50) per month.

Differences in entertainment are important to a young woman like Ernestina. She notes,

Here [in Victoria] there is nothing to do, but there [in Mexico] we had dances every Saturday night with lights, sound from big speakers and taped music, they went all night. They had all the popular music.

I ask her about the dances that they have in Victoria about once a month.

Yes, they are fun, but it's purely marimba music, and we get bored of all the same songs, it does not go on very late either, since every one has to get up early to go work in the fields.

Ernestina is wearing a polka dot blouse and shorts, her hair is loose, not back in a braid like the majority of the indigenous women in the region. I ask her about clothes, and if she has a traditional traje (dress) like her mother. She tells me that she does, but she does not wear it or like it.

I used to wear it before, but when we were in Mexico we were embarrassed to wear our traditional clothes, they didn't like it, they thought it was strange and people would stare at us so we changed to Mexican style.

The children in Ernestina's family rarely speak their Mayan language, Mam.

My mother cannot speak Castellano (Spanish), so we speak Mam with her. But my younger brothers and sisters don't answer me when I speak to them in Mam.
I ask her why this is, and she tells me that the kids are embarrassed to speak their native language, that other kids would not understand them in the camps in Mexico and would tease them. I ask Ernestina if she thinks it is important to keep their Mam culture, and she says
Yes, of course it's important. When we were in Mexico in the camps peo- ple would come and talk to us, peo- ple from the church I think, they would talk to us about Guatemala, talk to us about how important it is to remember our customs and our lan- guage. We should remember, it's part of us.

Ernestina's decision to return with her family was difficult for her. She did not want to be separated from her family-although her older brother and his wife were going to stay-or from her friends. Most of her friends did not want to return and stayed in Mexico. On the other hand, she notes that

\begin{abstract}
My parents really wanted to return. They are accustomed to Guatemala, this is where they were born, and where they want to be, but I have adapted to Mexican life style and I wanted to stay. When I first got here from Guatemala I saw the mud and the sticks and the life, and I wanted to cry, I wanted to go back. I think I still do, but I remember that when we first got to Mexico, my older sisters, and my parents were really upset, they missed the jungle, and the rivers, they missed Guatemala a lot.
\end{abstract}

Ernestina says she is going to give the experiment in returning some time, time to get used to Victoria, to Guatemala, and to her new life. She hopes there will be a chance to work as an education promoter next year, and that maybe she will meet someone and get married. She jokes that maybe, if and when she can get a gas-powered electricity generator, she will be able to watch television once again.

\section{Youth and the Future of the Return Community}

Ernestina's is not an isolated case among the youth that returned from the Yucatán region of Mexico. Many others share her difficulties in fitting 
into the relatively isolated agrarian lifestyle. In contrast, returnees from Chiapas seem to be happier at home and have more fully embraced the spirit of the return. They had not been influenced by the tourist areas and their lifestyle in Chiapas was not that different from Guatemala.

When I visited a camp called Porvenir (the future) in Chiapas, I discovered that the majority of youths were returning with their families. Later, talking to people in the return community of Victoria 20 de enero in Guatemala, it was evident that the youths from the Chiapas camps were committed to marriage, finding land and to staying. Many were becoming involved in the youth group CODAJUGUA. This group was started in the camps in Mexico, and is beginning to network with other youth groups in Guatemala. Their principle aim is to stop forced military recruitment by the Guatemalan army. They are also trying to organize youth activities in the community, such as team sports, tournaments and workshops on poetry, writing, music and art. Although they are well organized, it is a struggle due to lack of resources.

These youth activists will be a strong voice in the popular movement for a more just and democratic Guatemala. There is little doubt that the new generation is critical to change. Yet, finding a balance between the new and the old is going to be a struggle. The culture and identity changes which they bring with them from Mexico will be both a source of strength and a potential distraction. They will need to find ways to retain elements of their traditional Mayan heritage while entering into the politics and economics of a more integrated "global" world. Western consumer culture will be a particular challenge to finding this balance. It is important that the diversity and special needs of youths among the return communities be recognized. By understanding and supporting their views, outsiders can contribute to the solidarity behind a successful return and the quest for justice and democracy in Guatemala.

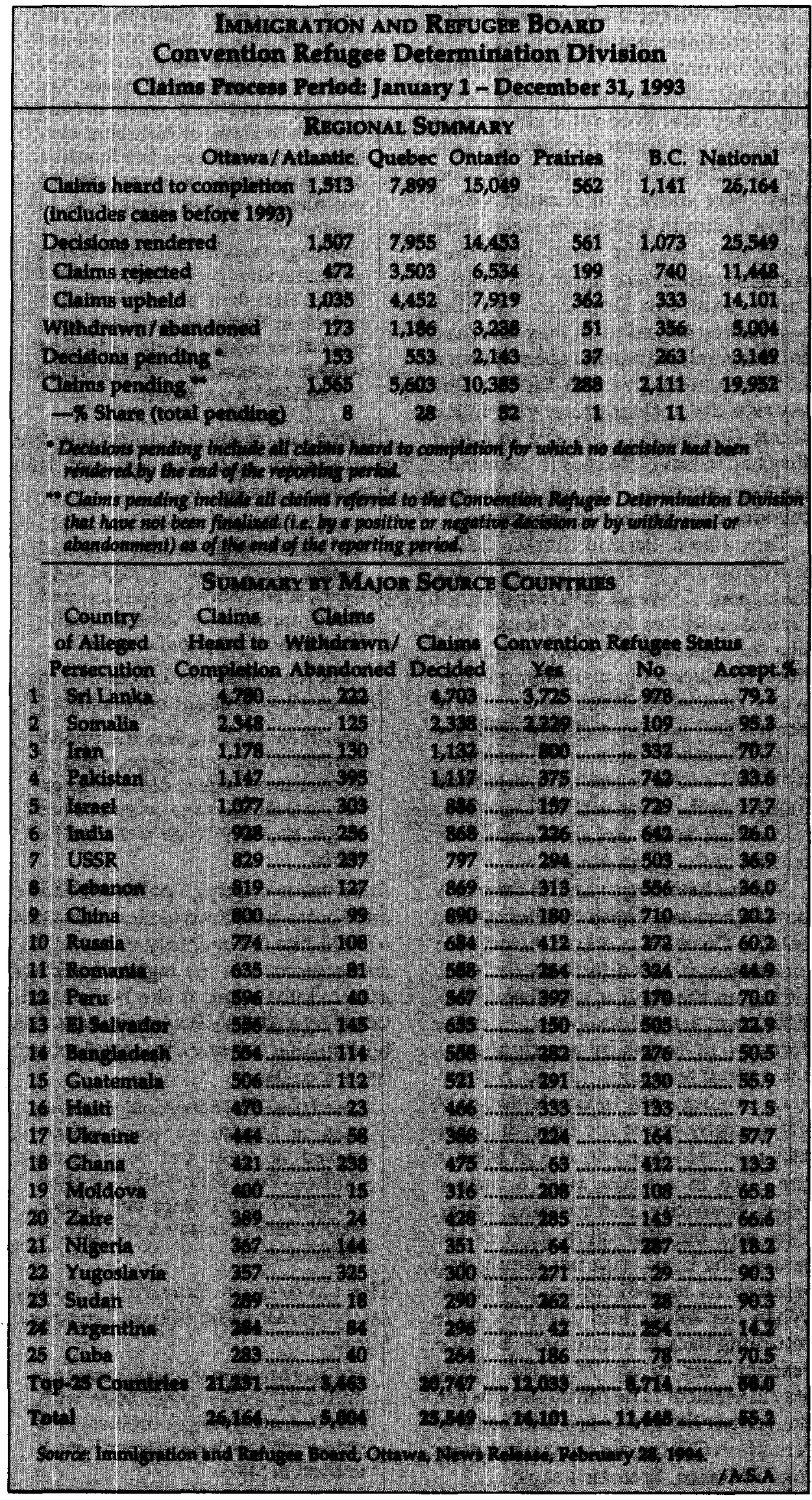

